NBER WORKING PAPER SERIES

\title{
NOMINAL WAGE STICKINESS AND \\ AGGREGATE SUPPLY IN THE GREAT DEPRESSION
}

Ben S. Bernanke

Kevin Carey

Working Paper 5439

\author{
NATIONAL BUREAU OF ECONOMIC RESEARCH \\ 1050 Massachusetts Avenue \\ Cambridge, MA 02138 \\ January 1996
}

We thank Ilian Mihov for research assistance, and Olivier Blanchard, Bo Honore, James Powell, Peter Temin, Mark Watson, and two anonymous referees for comments. The National Science Foundation provided research support. This paper is part of NBER's research program in Economic Fluctuations. Any opinions expressed are those of the authors and not those of the National Bureau of Economic Research.

() 1996 by Ben S. Bernanke and Kevin Carey. All rights reserved. Short sections of text, not to exceed two paragraphs, may be quoted without explicit permission provided that full credit, including $\odot$ notice, is given to the source. 


\title{
NOMINAL WAGE STICKINESS AND AGGREGATE SUPPLY IN THE GREAT DEPRESSION
}

\begin{abstract}
Building on earlier work by Eichengreen and Sachs, we use data for 22 countries to study the role of wage stickiness in propagating the Great Depression. Recent research suggests that monetary shocks, transmitted internationally by the gold standard, were a major cause of the Depression. Accordingly, we use money supplies and other aggregate demand shifters as instruments to identify aggregate supply relationships. We find that nominal wages adjusted quite slowly to falling prices, and that the resulting increases in real wages depressed output. These findings leave open the question of why wages were so inertial in the face of extreme labor market conditions.
\end{abstract}

Ben S. Bernanke

Woodrow Wilson School

Princeton University

Princeton, NJ 08544

and NBER

\author{
Kevin Carey \\ Department of Economics \\ University of Miami \\ PO Box 248126 \\ Coral Gables, FL 33124
}




\section{Introduction}

The problem of explaining why the world economy collapsed in the 1930 s has provided a difficult challenge to economists for more than six decades. Thus it is particularly exciting that in the last few years there has developed something of a new consensus about the sources of the Great Depression. The distinctive claim of this emerging view--which is based on the research of a number of scholars and has been given an authoritative treatment by Eichengreen [1992]--is that the proximate cause of the world depression was a structurally flawed and poorly managed international gold standard.

A brief synopsis of the "gold standard theory" of the Depression is as follows: For a variety of reasons, including among others the desire of the Federal Reserve to curb the U.S. stock market boom, monetary policy in several major countries turned contractionary in the late 1920s--a contraction that was transmitted worldwide by the gold standard [Hamilton 1987, 1988; Temin 1989].1 What was initially a mild deflationary process began to snowball when the banking and currency crises of 1931 instigated an international "scramble for gold". Sterilization of gold inflows by surplus countries, substitution of gold for foreign exchange reserves, and runs on commercial banks all led to increases in the gold backing of money and--consequently--sharp, unintended declines in national money supplies [Bernanke 1995]. Monetary contractions were in turn strongly associated with falling prices, output, and employment. Effective international cooperation could in principle have permitted a simultaneous monetary expansion despite gold-standard constraints, but disputes over reparations and war debts and the insularity and inexperience of the Federal Reserve, among other factors, prevented this outcome. As a result, individual countries were able to escape the deflationary vortex only 
by unilaterally abandoning the gold standard and re-establishing domestic monetary stability, a process which dragged on in a halting and uncoordinated manner until France and the other Gold Bloc countries finally left gold in 1936 [Eichengreen and Sachs 1985].

The gold standard theory's main contribution is that it largely solves what might heuristically be called the "aggregate demand puzzle" of the Depression: namely, why did sharp declines in nominal aggregate demand take place nearly simultaneously in so many countries in the early 1930 ? As we have noted, the theory's answer is that aggregate demand was depressed by a (largely unplanned) monetary contraction, which was transmitted around the world by the gold standard. However, the gold standard theory leaves unsolved the corresponding "aggregate supply puzzle", viz.: Why were the observed worldwide declines in nominal aggregate demand associated with such deep and persistent contractions in real output and employment? or, in the language of contemporary macroeconomics, how can we explain what appears to be a massive and very long-lived instance of monetary non-neutrality?

Explicitly or implicitly, most proponents of the gold standard theory have invoked "sticky" nominal wages as the reason for the protracted real impact of the monetary contraction. However, in contrast to the attention paid to the determinants of aggregate demand, recent research on the Depression has included very little analysis of aggregate supply in general or the sticky-wage assumption in particular. In the introduction to his 1992 book, Eichengreen alludes to the issue as follows:

"However devastating this initial disturbance [the deflationary shocks], one would think that at this point the self-equilibrating tendencies of the market would come into play. Wages and other costs should have fallen along with prices to limit the rise in unemployment and the decline in sales. They did so only modestly." (pp. 15-16) 
Eichengreen goes on to sketch a brief but intriguing explanation, based on the notion of coordination failure, for why wages and other costs failed to adjust. But he does not return to develop this explanation in the main part of the text, and the rest of the 450-page volume makes only a few passing references to the issue of wage adjustment.

In the context of the Great Depression, the relatively uncritical acceptance of the sticky-wage assumption is surprising. During the 1930 s many forces that Keynesian economists commonly point to as conducive to slow wage adjustment appeared relatively weak in most countries: Union power was at a low ebb, government's role in labor markets was generally more limited than today, price declines were too large and well-publicized for money illusion to be widespread, and the existence of an army of the unemployed must have significantly reduced workers' bargaining power. Given these conditions, it would seem reasonable to expect wage adjustment to be fairly rapid. At the same time it must be conceded that something prevented the world's economies from adjusting to the deflationary shocks of the 1930s, and there is a dearth of alternatives. 2 Thus the solution to the aggregate supply puzzle of the Depression remaing very much an open issue.

The purpose of this paper is to re-examine, from a comparative international perspective, the empirical evidence on the role of wage stickiness in the Depression. We take as our starting point the important work of Eichengreen and Sachs $[1985,1986] .^{3}$ Section II begins by recapitulating a key bit of evidence offered by Eichengreen and sachs in support of a role for wage stickiness in the Depression: a cross-sectional regression (using data from ten industrialized countries for the year 1935) of industrial production against the real wage. As we discuss further below, under the maintained assumption that cross-sectional differences in economic 
performance as of 1935 were due primarily to differences in gold-standard (monetary) policies, this simple regression has the important strength that it identifies a component of the aggregate supply relation. On the other hand, as we also discuss, the Eichengreen-Sachs regression is subject to a number of potentially important criticisms, both substantively economic and more narrowly econometric.

Section III presents new estimates of the link between output and wages that attempt to address the problems with the original Eichengreen-Sachs results and to clarify the role of wage stickiness in the Depression: We use a larger data set than they did, covering 22 countries over the period 19311936. We deal with residual simultaneity bias, using aggregate demand shifters as instruments, and make a number of other econometric corrections. We also allow for dynamic influences (by incorporating lagged dependent variables) and account for other factors (such as banking panics and work stoppages) that may have affected aggregate supply. We augment our analysis of the relationship among wages, prices, and output by estimating a wage adjustment equation, which provides information on how quickly nominal wages responded to changes in the price level and in unemployment rates. Finally, we provide joint estimates of the aggregate supply and wage adjustment equations, imposing cross-equation restrictions.

Despite the many modifications, our findings broadly concur with the original conclusions of Eichengreen and Sachs. The econometric evidence offers reasonably strong support for the hypothesis that slowly-adjusting nominal wages helped propagate monetary shocks in the Depression. This empirical finding leaves open the deep question of why wages did not adjust more quickly in the interwar period. Section IV summarizes the findings, 
makes some conjectures about why wage adjustment in the Depression appears to have been so slow, and gives suggestions for future research.

\section{Aggregate Supply in the Depreanion: The Elchengreen-Sache Bvidence}

Many of the key elements of the gold standard theory of the Depression were originally set out in two important papers [1985, 1986] by Eichengreen and Sachs, hereafter E-S.4 The 1985 E-S paper is the basic statement of their view that the interwar gold standard was the principal carrier of the deflationary virus; and that devaluation or abandonment of the gold standard-rather than being a counterproductive or even hostile (i.e., "beggar-thyneighbor") act--was in fact the essential first step to national and world economic recovery.

The primarily historical mode of analysis in E-S [1985] is complemented by the theoretical analysis of their 1986 article, which lays out a simple two-country model. The main contribution of this model is to extend the conventional Mundell-Fleming framework to incorporate the links between gold reserves and the money supply under a gold standard. For our purposes here, the key part of that model is the two-equation "aggregate supply block":

(1) $q_{1}=-\alpha\left(w_{1}-p_{1}\right)$

(2) $w_{1}=\bar{w}$,

where $q$ is real output, $w$ is the nominal wage rate, $p$ is the price level, and subscripts indicate the time period. All variables are in logs and the constant term in equation (1) is omitted. Equation (1) states that the output supplied by industry depends negatively on the real wage, which firms treat as 
parametric. We refer to equation (1) as the output supply equation, to distinguish it from the aggregate supply equation, in which the price level is the only contemporaneous endogenous variable appearing on the right-hand side. Equation (2) is the wage adjustment equation, which describes the evolution of the nominal wage; here this equation is trivial since, for expositional purposes, E-S made the extreme assumption that the nominal wage is exogenously fixed. We relax this assumption in section II below. Substituting (2) into (1) yields the aggregate supply equation of the $E$ s model:

(3) $q_{1}=-\alpha\left(\bar{w}-p_{1}\right)$.

As is conventional, the aggregate supply equation (3) implies a positivesloping relationship between output and the price level, given the nominal wage. In postulating (3), E-S adopt the traditional Keynegian view that price increases raise aggregate supply by lowering the real wage faced by firms.5 In the empirical portion of their 1985 paper, E-S focused on the differences between the countries that abandoned the gold standard at a relatively early stage (notably the sterling bloc, consisting of Great Britain and her trading partners, which left gold subsequent to the 1931 crises) and those countries that remained on gold until the collapse of the system in 1935 and 1936 (the Gold Bloc, led by France). 6 Consistent with their view that monetary contraction enforced by the gold standard was the principal source of the Depression, they found that countries that left gold early enjoyed much more rapid recoveries than those that stayed on gold; and that this difference in performance was associated with earlier reflation of money stocks and price 
levels in the countries leaving gold (see Bernanke and James [1991] and Bernanke [1995] for detailed evidence on these points).

As a test of their hypothesis about the role of wages in aggregate supply determination, E-S presented a cross-sectional regression lusing data from ten industrial countries for the year 1935) of industrial production (measured as an index, $1929=100$ ) against a constant and the real wage (also measured as an index, $1929=100$ ). Under their assumption that the differences among countries in 1935 were due primarily to differences in monetary policies (which shift the aggregate demand curve), this regression should identify the aggregate supply curve, equation (3) above. Their estimated equation was

$$
\text { Ind. Prod. } ._{1935}=\underset{(t=7.39)}{175.2}-\begin{aligned}
& \left.0.598 \text { (Real } \text { wage }_{1935}\right) \\
& (t=3.14)
\end{aligned} \quad \bar{R}^{2}=.50 ;
$$

i.e., E-S found a strong negative relationship across countries between output and real wages, as predicted by (3). In addition, a plot of their data (their Figure 2, p. 938) confirms their claim that adherence to the gold standard was strongly associated with high real wages and depressed output: The countries that fall in the high-real-wage, low-output region of their figure are all countries that remained on gold well beyond 1931 (France, Belgium, the Netherlands, Italy), while the countries with low real wages and higher output were members of the sterling bloc that left gold early (Finland, Denmark, Sweden, the United Kingdom, and Norwayl.

Our Figure I expands the E-S sample by showing industrial production and real wage data (both measured relative to $1929=100$ ) for 22 relatively industrialized countries, for each year from 1931 through 1936 (i.e., all 
years in which there were a significant number of countries both on and off the gold standard). Countries in the sample, with mnemonic abbreviations, are listed in Table I. Included in the sample are all countries for which annual aggregate nominal wage series for 1929-36 were published by the International Labor organization ${ }^{7}$, and for which we could also find matching output and price level data. Industrial production and wholesale price indices (used to deflate the wage series) are from the League of Nations (Statistical Year Book, various issues), except for Argentine IP data, which are from Thorp [1984]. The choice of a wholesale price index as a deflator (as in E-S) is dictated by data availability. In Figure I, countries that were on the gold standard for more than half the year in a given year are designated by capital letters; countries off the gold standard in a given year are indicated by lower-case letters. ${ }^{8}$

Figure I has several interesting features. First, note the countercyclicality of real wages in the great majority of countries: Real wages during 1931-34 (the worst part of the slump) were between 20 and 40 ? higher than in 1929 in most countries, the result of sharp declines in price levels not accompanied by comparable falls in nominal wages. In contrast, by 1936 real wages in most countries had dropped significantly (as prices rose and nominal wages fell), to a range centered at about 10t higher than 1929 . At the same time that real wages fell, world output and employment grew substantially from Depression-era lows. This pattern of output, wages, and prices over time is consigtent with the E-S interpretation of the link between wages and aggregate supply.

Also apparent in Figure I is the evolving cross-sectional relationship between output and real wages: At the beginning of the period (particularly in 1931), little cross-sectional variation in the two variables can be seen. 
From the perspective of the E-S hypothesis, this lack of variation may be ascribed to the fact that, as of 1931 or 1932 , most countries were either on the gold standard or had recently left it, and thus had experienced similar shocks to aggregate demand. However, as gold standard (and hence monetary) policies diverged over time, cross-sectional variations in the state of aggregate demand increased, and the negative relationship of output and real wages became apparent. For the later years, particularly 1935 and 1936, the scatter plots show a downward-sloping relationship between output and the real wage similar to that found by E-S. Further, the countries we have added to the data set conform in almost all cases to the E-S observation that Gold Bloc countries (such as Switzerland and Poland) had high real wages and low output, while countries that abandoned gold early on (Japan, Australia, New Zealand, and Argentina, for example) had lower real wages and higher production by the middle of the decade. Thus, in general, the cross-sectional pattern displayed in Figure I also seems supportive of the E-S view.

In summary, the E-S evidence, as simple as it is, has two important strengths. First, it demongtrates that cross-country differences in monetary policy during the Depression era (associated with membership or non-membership in the gold standard) provide an unusually good opportunity to identify the aggregate supply curve. Second, the basic E-S regression discussed above--as well as the extended data set displayed in Figure I--appears consistent (at least) with the role for sticky wages postulated in the E-s model of the Depression.

Nevertheless, there are a number of substantive criticisms that can be made of the E-S approach. In the rest of this section we describe four general weaknesses of the $\mathrm{E}-\mathrm{S}$ evidence. In section III we provide new 
estimates of the determinants of aggregate supply in the interwar period that address each of these weaknesses.

A. The Eichengreen-Sachs Evidence: a Critique

Potential reservations about the E-S empirical results include:

(1) Small sample size. As has already been stressed, the E-S regression uses data for only one year and ten countries. Below we present estimates employing our larger data set.

(2) Simultaneity bias. We have emphasized E-S's insight that--under the maintained assumption that differences in national economic performance during the Depression can be attributed primarily to differences in the state of aggregate demand--cross-sectional data may be used to identify aggregate supply relationships. However, strictly speaking, their use of an oLs regression requires the assumption that 100 of the observed cross-sectional variation be due to aggregate demand factors, of to factors shifting aggregate supply. This assumption, besides being rather implausible a priori, is difficult to square with the absence of a downward-sloping relationship between output and real wages in 1931 and 1932 . Hence, it seems worthwhile to explicitly incorporate aggregate demand shifters as instruments, in order to identify the aggregate supply relationships and eliminate remaining simultaneity bias.

(3) Specification issues. The simple specification utilized by E-S raises a number of concerns. First, the output supply equation (eq. (I)) used by $\mathbf{E}-\mathrm{S}$ does not acknowledge the possibility that other factors might have affected supply, given the real wage. We introduce additional supply shifters in section III below. Second, the output supply equation used by E-s contains no dynamic element; in particular, no allowance is made for the possibility of 
adjustment costs in output. Third, the assumption that the nominal wage is exogenously fixed is obviously over-simple (and counterfactual). Below we present estimates of wage adjustment equations which allow nominal wages to respond to changes in the price level and the unemployment rate.

(4) The wage effect versus the price effect. The E-S evidence (and Figure I) makes clear that there was an inverse cross-sectional relationship between output and real wages during the Depression era, especially in 193336. However, it is important to ask whether there are any alternative explanations for this observed relationship besides sticky nominal wages. It seems to us that explanations of the output-real wage relationship not involving nominal shocks and non-neutrality--i.e., purely "real" explanations--can largely be ruled out. Adverse technology shocks would induce low, not high, real wages in depressed countries. Spending reductions due strictly to real factors, plus imperfect competition and countercyclical markups, could in principle reproduce the observed patterns; but we are not aware of any plausible story of why these declines in spending should have affected so many disparate countries around the world nearly simultaneously, and in particular why they should have been more persistent in countries remaining on the gold standard. Similarly, negative labor supply shocks could in principle generate both high real wages and falling output; but again, there is no reason why labor supply shocks should have hit only Gold Bloc countries after 1931 and not the countries that abandoned gold. Further, the observed changes in output and the real wage are simply too large in magnitude to be comfortably reconciled with a labor supply story. 9

Although the evidence for a non-vertical aggregate supply curve in the Depression era is strong, it is important to note that the E-S regression of output on the real wage cannot by itself distinguish whether the non- 
verticality of the aggregate supply curve in the interwar period is due to imperfect adjustment of nominal wages, or to some other connection between the prices and aggregate supply (such as debt-deflation, for example).10 For a thought experiment that illustrates this point, suppose it were the case that 1) the nominal wage data consisted entirely of measurement error, uncorrelated with anything else, and 2) falling prices caused output to decline, but for some other reason than an increase in the (correctly measured) real wage. Under these assumptions, the real wage variable in the E-S regression would simply equal the price variable plus noise, and the estimated coefficient on the real wage would be a (downward-biased) estimate of the impact of falling prices on output. In this thought experiment, the link between deflation and output would be erroneously attributed to the real wage channel, even though by assumption there is no real wage effect.

Ideally, this identification problem would be dealt with by specifying the alternative channels linking prices and output and including the appropriate proxies in the regression along with the real wage. However, if there are missing data, measurement errors, or uncertainties about the nature of the alternative channels, there may be a bias toward finding a real wage effect even if none exists. To distinguish effects on output operating through wages and other effects operating solely through prices, in the estimates of the output supply equation reported in the next section we allow nominal wages and prices to enter separately, then test whether their estimated coefficients are equal and opposite, as should be the case if only wage effects are operative. 


\section{Depresalon-8ra Aggregate supply Reletionehipa: Now setimates}

The shortcomings of the E-S evidence described above lead us to undertake a more comprehensive econometric analysis of interwar aggregate supply relationships. We present, in turn, new estimates of the output supply equation, which relates output supplied by firms to the real wage; estimates of the wage adjustment equation, which describes the adjustment of nominal wages to prices and other factors; and joint estimates of the aggregate supply equation (relating output to the price level) and the wage adjustment equation. In each case our main interest is to assess empirically whether slow adjustment of nominal wages was an important factor in the Depression. All of our estimates utilize the panel data set described in the previous section (22 countries, 1931-1936; data for 1929 and 1930 are available for use when lagged data are needed). Reflecting the panel nature of the data, each estimated equation includes country fixed effects and year dummies. Year dummies--the most flexible way of allowing for time effects-were employed after more parsimonious ways of allowing for time variation, such as trend terms, were tried and statistically rejected. The use of free year dummies implies that the identifying power in the following estimates is obtained essentially only from cross-sectional variation, albeit for each year in the sample.

A. The output Supply Equation

For estimation purposes, we replace the E-S output supply equation, equation (1), with the following:

(4) $\quad q_{1}=-\alpha_{w} w_{1}+\alpha_{P} p_{1}+\delta q_{1-1}+X_{1} \beta+\varepsilon_{1}^{q}$ 
Equation (4) incorporates a number of generalizations to the E-S output supply equation. First, we allow nominal wages and prices to enter the equation separately; we then test the restriction, implicit in the E-S specification, that the coefficients $\alpha_{W}$ and $\alpha_{P}$ are equal. As discussed in the previous section, this procedure allows us to separate aggregate supply effects entering through nominal wages from other effects working through the price level alone. This approach puts a higher burden of proof on the stickywage channel, since separate wage effects will be identified only if there are autonomous shocks to nominal wages, and if the wage data are not excessively noisy. Since we do generally find important wage effects, this conservative approach is appropriate.

Second, (4) introduces lagged output into the output supply equation. The addition of this variable is motivated by the presumption that there exist adjustment costs (in hiring or in reactivating facilities, for example) which prevent extremely rapid changes in national output. In the absence of a term in lagged output, the output supply equation implies that a decline of real wages to their normal level would induce a complete recovery of output within the year, no matter how severely depressed the economy is initially. This implication of omitting lagged output seems implausible. As is well known, however, inclusion of the lagged dependent variable may result in inconsistent estimates if there is serial correlation in the error term. To deal with this problem, we employ a nonlinear least squares (NLLS) procedure to obtain consistent estimates of both the serial correlation coefficient (assumed to be common to all countries) and the coefficient on lagged output. II

Third, the new term $X_{s} \beta$ in (4) reflects the possibility that other factors besides the real wages (and the time and country fixed effects) shift 
the output supply equation. In our estimates we include two additional regressors in equation (4):

(1) Bernanke and James [1991] found that a dummy variable indicating periods of banking panics, which they constructed from qualitative historical evidence, was an important explanator of output. Banking panics could shift the supply equation if they disrupted normal flows of credit to firms. To capture this effect, we include their dummy variable PANIC in some of the regressions reported below. Bernanke and James based this variable on a chronology of banking crises, reported in their paper. For each year and country, PANIC equals the number of months that the banking system was "in crisis". Periods of crisis are dated as starting from the onset of severe banking problems and ending either at some clear demarcation point (such as the U.S. bank holiday in March 1933) or, alternatively, after one year.

(2) In a number of countries, production was affected by large-scale strikes and lockouts. Thus we also add to the output supply equation the number of days lost to industrial disputes per thousand employees, or STRIKE (from various issues of the ILO's Yearbook of Labor statistics).

While the inclusion of these additional regressors should reduce the omitted variables problem, it remains likely that other, unmeasured factors also shifted the supply relationship: Possibilities include technological changes, shifts in the composition of output or the workforce, government policies affecting labor supply or work rules, and simple mismeasurement of regressors, to name a few. Since shocks to the supply of output should affect current wages and prices, simultaneity bias is a potential problem and instrumental variables are needed to obtain consistent estimates of the supply relation. 
As we have reiterated, the basic premise underlying the E-S interpretation of their own regression is that the output supply relation is identified by cross-sectional differences in aggregate demand conditions, which in turn are due primarily to differences in exchange rate and monetary policies. We followed this logic in constructing our instruments: First, we broke our sample into two sets of countries, those that abandoned gold in 1931 and those that remained on gold after 1931.12 The countries that left gold had effective control of their own monetary policies for all or most of our sample period, so for those countries we treat the log of M1 (money and notes in circulation plus commercial bank deposits, both from the League of Nations Yearbook, various issues) as an exogenous aggregate demand shifter.

Countries that remained on gold, in contrast, did not have control of their own money supplies.13 As specified in the E-S [1986] extengion of the Mundell-Fleming model, in small countries on the gold standard, domestic aggregate demand instead depends on the domestic-currency price of imports (determined by the foreign price level and the gold content of the domestic currency) and the domestic interest rate (determined by the world interest rate through interest-rate parity). Accordingly, we used the log of an import price index and the central bank discount rate (taken from the league of Nations Yearbook, various issues) as instruments for gold standard countries during the years in the sample that they were on gold.14 The import price index for each country on the gold standard was constructed as a weighted average of the domestic-currency prices of imports from each trading partner, using 1929 import shares as weights.15 For the portion of the sample period after each Gold Bloc country left gold, we used M1 as an instrument rather than the import price and the discount rate. 16 
For all countries, we treated the lagged nominal wage and lagged output as predetermined, and we took the PANIC and STRIKE variables to be exogenous (more precisely, to be uncorrelated with the disturbance in the output supply equation).17 Current and once-lagged values of the aggregate demand shifters were used as instruments, reflecting the fact that both current and lagged values of the price level appear in the NLLS specification that we use.

Before turning to the results, we must discuss one more technical issue, which relates to the treatment of panel data with fixed effects. In deriving the asymptotic properties of estimates and standard errors in this situation, it is generally assumed that the cross-section is "large", that is, asymptotic theory applies in the cross-sectional dimension. However, one may choose to regard the number of time units either as "large" (tending toward infinity) or "fixed". In the former case, our nonlinear instrumental-variables procedure, estimated with the variables in levels and with time and country dummies included, is consistent. Under the latter assumption, however, our procedure leads to inconsistent estimates due to correlation between the lagged dependent variable and the error term, which does not disappear for fixed $T$. The recommended procedure in the latter case is to difference the model and to use second and higher lags of the differenced lagged dependent variable as instruments (see Arellano and Bond [1991] for a recent discussion and application). Since in our case $T=6$ (excluding two observations reserved for lags), the fixed-T assumption seems more appropriate. On the other hand, with noisy data, the use of twice-lagged and differenced data as instruments is likely to produce quite imprecise results. Further, the application of this technique requires the sacrifice of two more years of data, reducing the sample period to 1933-1936 inclusive. As a compromise, we present both estimates obtained in levels with explicitly estimated fixed effects (i.e., 
estimates based on the "large-T" assumption), as well as estimates obtained in a differenced specification with the appropriate lagged instruments (relevant under the "fixed-T" assumption).

We are now ready to turn to Table II, which reports estimated versions of the output supply equation that include various combinations of the three additional regressors (PANIC, STRIKE, and lagged output). Results estimated with levels and country dumies are reported in Panel $A$, and results from the differenced specification are given in Panel $\mathbf{B}$. We report point estimates and t-statistics for the coefficient on each regressor, as well as for the serial correlation coefficient. The final column of Table II indicates the p-value of the hypothesis that the nominal wage and the price level enter the equation with equal and opposite signs (i.e., $\alpha_{W}=\alpha_{p}$ ), with a small entry indicating that this hypothesis can be rejected.

The results are interesting. First, there is strong support for the inclusion of lagged output in the equation, indicating the existence of adjustment costs in production. In the presence of lagged output, the serial correlation coefficient is typically estimated to be insignificantly different from zero, and it is often negative.

second, the auxiliary variables, PANIC and STRIKE, generally make contributions to the equation that are highly significant, both economically and statistically. For example, in the equation with all variables included (either line 4 or line 8), the estimated effect of a banking panic on output is about 1.0 percentage points per month, with a t-statistic of around four; i.e., the median-sized banking crisis, which under the Bernanke-James assumptions lasted twelve months, was associated with a loss of about twelve percentage points of output growth (Bernanke and James [1991] found an effect of similar magnitude). The coefficient of STRIKE is significant statistically 
$(t=3.58)$ and of reasonable magnitude in the levels specification with all variables included (line 4).18 However, STRIKE's coefficient is insignificant and of the wrong sign in the differenced specification (line 8), possibly because of the shortened sample period used in that specification.

The most important results relate to the effects of wage and price movements on output. Table II shows that, in all specifications, both the nominal wage and the price level enter the output supply equation significantly 19 and with the expected sign. The long-run elasticity of output with respect to the real wage (taking into account the presence of the lagged dependent variable) generally is estimated to exceed one. Further, as the last column shows, the hypothesis that wages and prices enter the equation with equal and opposite signs is never close to rejection, which is consistent with the view that prices affected output through only the real-wage channel (given that the effects of deflation operating through banking panics have been controlled for).

Thus, generalizations of the E-S regression including the use of a larger, panel data set; allowing for separate wage and price effects; allowing for additional output supply shifters and dynamic effects; using instruments to correct for simultaneity bias; and with additional econometric corrections, lead to results that support E-S's original interpretation of the data, that the inverse relationship of output and real wages reflects largely the effects of incomplete nominal wage adjustment in the presence of aggregate demand shocks. 


\section{B. The Wage Adjustment Equation}

In their work, E-S made the simplifying assumption that the nominal wage is literally rigid. For increased empirical realism, we replace the simple ES wage adjustment equation, (2), with the following:

$$
w_{1}=\lambda_{P} p_{1}+\lambda_{w} w_{1-1}-\gamma u_{1}-\theta\left(\Delta u_{1}\right)+\varepsilon_{1}^{w}
$$

In (5), $\lambda_{P}$ measures the degree to which nominal wages respond to contemporaneous price movements and $\lambda_{W}$, the coefficient on the lagged nominal wage, is a measure of nominal inertia. 20 If wages follow the partial adjustment mechanism usually assumed, then $\lambda_{P}+\lambda_{W}=1$; we do not impose this condition but instead test for it. The partial adjustment mechanism typically presumes that the wage is adjusting toward a "desired" or equilibrium level: In (5), following much work on the phillips curve for both the interwar and postwar periods, we allow the desired wage level to be affected by both the unemployment rate $u$ and the change in the unemployment rate, $\Delta u$; variations in the desired real wage over time and space are also accommodated by the time dummies and country fixed effects.

The new data required to estimate equation (5) are unemployment rates. Data on industrial unemployment rates for each year in the sample were available for 14 of the 22 countries in our sample. 21 Unemployment rates for the remaining eight countries were constructed by regressing the change in unemployment against the change in industrial employment for countries for which both series were available, then applying the estimated coefficients to employment data for countries with no unemployment data.22 Estimates of the wage adjustment equation for the subsample of countries with non-interpolated unemployment data were similar to those reported below and are not given here to save space. 
As in the case of the output supply equation, we use a nonlinear procedure to obtain consistent estimates in the presence of a lagged dependent variable and possible serial correlation, and use instruments to correct for simultaneity bias. Instruments include the aggregate demand shifters described above and lagged wages or lagged differenced wages, as appropriate. In equations including unemployment or differenced unemployment, lagged unemployment or lagged differenced unemployment are added to the instrument list.

The estimates of the wage adjustment equation are reported in Table III. As in Table II, Panel A contains estimates for the variables in levels with explicit fixed effects, and Panel B gives the results estimated in differences, with twice-and thrice-lagged differences of the lagged dependent variable as instruments. (We do not include the specification including differenced unemployment in panel B, since that would require us to use a second difference of unemployment in estimation; the second difference of these unemployment data seems unlikely to contain much information.) The final column of Table III gives $p$-values for the hypothesis that the coefficients on the price level and the lagged nominal wage sum to one, as is implied by the partial adjustment model.

Two general conclusions can be drawn from Table III: First, estimates of the wage adjustment equation appear to provide further evidence of nominalwage stickiness. Nominal wages are found to depend on both current prices and lagged nominal wages with coefficients that lie between zero and one. The coefficients on the current price level are generally estimated to be in the vicinity of 0.2-0.4 and are typically six or seven standard deviations below one, the theoretical value of if wages adjust completely within the year to aggregate demand shocks. Estimated coefficients on lagged nominal wages are 
significant or near-significant. Taken together, the results suggest a substantial degree of stickiness in wage adjustment; in particular, the hypothesis that wages adjust immediately to price changes arising from aggregate demand shocks $\left(\lambda_{P}=1, \lambda_{W}=0\right)$ can always be rejected at $\mathrm{p}=.000$ (not shown in the table). On the other hand, the restriction imposed by the partial adjustment model of wages $\left(\lambda_{P}+\lambda_{W}=1\right)$ is also generally rejected, though not nearly so sharply, as shown by the last column of Table III. second, a higher unemployment rate does seem to imply lower nominal wages, all else equal (see lines 2 and 6 ), although in these estimates the level of statistical significance is low (possibly because of poor instruments ${ }^{23}$ ). Interestingly, in the light of other results that have been obtained, the level of unemployment seems to be more relevant to wage determination in this sample than is differenced unemployment: Unemployment enters with greater statistical significance than differenced unemployment when both are included in the regression (line 3), although the coefficients are similar, and differenced unemployment enters with the "wrong" sign when the level of unemployment is excluded (line 4 ).

C. Joint Estimation of the Wage Adjustment and Aggregate Supply Equations To this point we have estimated the component equations of the aggregate supply block individually. We close this section by reporting estimates of the aggregate supply block as a whole, with cross-equation restrictions imposed and with allowance for correlation of contemporaneous equation residuals. This joint estimation is both more efficient and also permits direct estimates of the aggregate supply equation, as opposed to the output supply equation estimated above. 
If we substitute the wage adjustment equation (5) into the output supply equation (4), we obtain the aggregate supply equation:

$$
q_{1}=\alpha\left(1-\lambda_{P}\right) p_{1}-\alpha \lambda_{w} w_{1-1}+\alpha \gamma u_{1}+\delta q_{1-1}+X, \beta+\left(\varepsilon_{l}^{q}-\alpha \varepsilon_{l}^{w}\right)
$$

The aggregate supply equation links current output to the current price level, the output supply shifters (PANIC and STRIKE), and the lagged level of output (reflecting adjustment costs). Output is also affected by the lagged nominal wage and the current unemployment rate, through the effect of those two variables on the current nominal wage (we omit the differenced unemployment rate here). In (6) we have imposed the restriction $\alpha_{W}=\alpha_{P}=\alpha$, which is accepted by the data (Table II), but we do not impose $\lambda_{P}+\lambda_{w}=1$, which is generally rejected (Table III).

Joint estimates of the parameters of the aggregate supply equation (6), and the wage adjustment equation (5), are provided in Table IV. Results are presented for both the levels and differences specifications, and both with and without inclusion of the unemployment rate in the wage adjustment equation. The instruments employed are the union of the instruments used for the output supply and wage adjustment equations separately. The correlation between contemporaneous residuals of the two equations is unrestricted. Based on the results of Tables II and III, and for simplicity, we apply the serial correlation correction only for the wage adjustment equation (levels specification). Estimates of the serial correlation coefficient for that one case, as well as other equation diagnostics, are provided at the bottom of the table.

The results complement those already reported. In the levels specification, estimates are of the right sign and general magnitude, and are 
in almost all cases significant. The estimates allow us to reject the hypothesis of vertical aggregate supply (complete within-period adjustment of wages to the price level, i.e., $\lambda_{P}=1, \lambda_{W}=0$ ) with a high degree of confidence $(p=0.000)$. Interestingly, in this specification the role of unemployment in depressing nominal wages is found to be much larger and more statistically significant than it is when the wage adjustment equation is estimated by itself.

The differences specification (which, recall, is estimated for the 19331936 period) yields qualitatively similar results (with lower statistical significance, as expected), with two exceptions. First, as before, the STRIKE variable does not enter significantly in the differences specification. second, and more importantly, nominal-wage effects (as reflected in the parameters $\alpha$ and $\lambda_{W}$, are smaller and less statistically significant. The latter result appears to be due to the fact that the log-difference of the wage is poorly predicted by the available instruments. However, because the coefficient $\lambda_{p}$ is well-identified in these estimates, the hypothesis of complete wage adjustment to price changes can still be rejected at $p=.000$.

As in Tables II and III, the results reported in Table IV omit estimated year effects, to save space. In brief, the time dummies are found to play very little role in the wage adjustment equation, either in terms of magnitude or statistical significance; a similar remark applies to the estimates of the wage equation in Table III. Estimated year effects are more important in the aggregate supply equation (and similarly, in the output supply equations in Table II): In these equations the time dummies capture what appears to be a fairly rapid increase in average potential output over the period 1931-1933, and a slower increase between 1933 and 1936. However, the estimated year effects capture little of the short-run variation in output (and, of course, 
none of its cross-country variation) and therefore do not account for a particularly large component of the overall explanatory power of our specification.

\section{A Final Specification Issue: Aggregation Bias}

This paper has shown that, all else equal, higher nominal wages were associated with lower real output during the 1931-36 period. However, the wage data we have used are aggregate indexes, about whose construction we know less than we would like. We believe that in most cases these wage indexes were constructed by dividing aggregate payrolls by aggregate hours of work. If so, then there may be reasons to worry that our finding of a negative relationship between output and wages is spurious: First, if errors in measuring hours of work and output are positively correlated, as seems likely, then a spurious negative relationship between measured output and the measured wage will be induced. Second, a spurious negative relationship might also arise because of changes in the composition of the work force over the cycle. For example, if employers were more likely to fire their low-skill, low-wage workers as output declined, then the aggregate wage would be observed to rise as output fell. A similar bias would result if employment losses in low-wage industries were greater than those in high-wage industries, although this seems empirically less likely.

We were able to address the aggregation issue by using occupational wage data, reported in various issues of the International Labor organization's Yearbook. The ILO reported wage rates for a number of occupations within seven industries, for as many as nine countries. The numbers reported are clearly wage rates rather than average hourly earnings (one indication is that they sometimes remain unchanged for several years at a time). Another nice 
feature of these data is that the particular industries included span major sectors of the economy, including not only manufacturing but construction, utilities, transport, and government.

For each industry, we chose an occupation which seemed representative and for which all the data were available (list of occupations available on request). After converting all wages into an index form $(1929=100)$, for each country we constructed a nominal wage index as the simple average of the occupational wages. In principle, these wage indexes should avoid the aggregation problems alluded to above, since they are based on wage rates (not average hourly earnings) and are constructed using fixed weights. 24

The bias hypothesis says that the aggregate ILo wage indexes used in this study should lie above the corresponding fixed-weight indexes in the periods of lowest output. Of the nine countries for which comparison was possible, this implication seems to be true only for Australia and Estonia. For Canada, the Netherlands, and Sweden, we found that the aggregate wage index is actually below the fixed-weight index at the low point of the Depression, while for Denmark, the U.K., Italy, and to a slightly lesser extent France, the two wage indexes track closely. A regression of the aggregate wage index less the fixed-weight index against output, using country dummies, yields a coefficient on output of .041 , with a t-statistic of 1.22 . Hence the differential between the two indexes is found to be slightly procyclical, not countercyclical as would have to be the case to account for the observed negative relationship between output and the real wage. Thus it does not appear that aggregation bias in the construction of the wage data is driving our results. 


\section{Conclueton}

In concluding the paper, it is worth recapitulating the evidence that we have found in favor of a role for nominal-wage stickiness in the Depression. First, like Eichengreen and Sachs [1985], we verified that during much of this period there existed a strong inverse relationship (across countries as well as over time) between output and real wages; and also, that countries which adhered to the gold standard typically had low output and high real wages, while countries who left gold early experienced high output and low real wages. It does not appear that any purely real theory can give a plausible explanation of this relationship. Among theories emphasizing some type of monetary non-neutrality (i.e., a nonvertical aggregate supply curve), there are basically only two types: theories in which the price level affects output supply because of nominal-wage stickiness, and theories in which the price level affects output supply for some other reason. We find that, once we have controlled for lagged output and banking panics, the effects on output of shocks to nominal wages and shocks to prices are roughly equal and opposite. If price effects operating through non-wage channels were important, we would expect to find the effect on output of a change in prices (given wages) to be greater than the effect of a change in nominal wages (given prices); as we find roughly equal effects, our evidence favors the view that sticky wages were the dominant source of non-neutrality.

second, we have estimated wage adjustment equations that measure the sensitivity of current nominal wages to lagged nominal wages and current prices (instrumented by aggregate demand shifters). If wages were flexible, then wages would respond proportionally to prices in the face of a (nominal) aggregate demand shock, and would be unrelated to lagged wages. We are able to reject the hypothesis that wages respond fully to current aggregate demand 
shocks, and are not partly determined by lagged wages, with a high degree of statistical confidence.

Typically, studies of wage stickiness face the difficult problem of ascertaining whether an observed tendency of wages to adjust slowly has allocational consequences. For example, wages might just be "installment payments" in efficient labor contracts (Hall (1980)). It is worth stressing that the gold standard theory of the Depression generates a strong identifying restriction which helps us circumvent this problem, namely, that the dominant source of variation across countries was differences in money stocks and hence in levels of aggregate demand. Under this identifying restriction--which is not available in most other periods or in single-country studies--the correlation across countries of high nominal wages and low output is interpretable as an allocational effect of sticky wages. The Depression-era results should therefore be of interest to macroeconomists generally and not only to historians.

Our findings suggest several topics worthy of further investigation. First, the nature of our data set--panel data with many more countries than time periods--has led us to focus on cross-sectional relationships between output and real wages. More careful attention needs to be paid to the performance of the sticky-wage hypothesis in the time-series dimension--by using the higher-frequency data that are available for some countries, for example. It would also be of interest to look again at industry-level wage and output data, which are available for a number of countries.

Second, and more fundamentally, research is needed on the underlying reasons for slow wage adjustment in an environment which--as was discussed in the Introduction--would not seem conducive to wage stickiness. Coordination failure, as suggested by Cooper [1990] and Eichengreen [1992] represents one 
interesting direction. Politicization of wage- and price-setting, arising from the desire of various groups to protect their income shares, is another possible source of stickiness (Bernanke [1995] discusses this point in a bit more detail). It would also be interesting to perform a comparative study of interwar wage-setting institutions and regulations among some of the countries in this sample.

Finally, future work might consider the interactions of wage stickiness and other proposed solutions to the aggregate supply puzzle, such as the financial crisis hypothesis of Bernanke and James [1991]. For example, in the spirit of the financial crisis story, it may be that "high" nominal wages had their depressing effect on output primarily by increasing financial (i.e., cash-flow) pressures on firms, rather than through the conventional labor cost channel.25 (In the former scenario, the average worker's wage is the key variable determining output and employment; in the latter, conventional scenario, the key variable is the wage of the marginal worker.) In principle, the two channels of effect could be distinguished by comparing the effects of changing wages on employment in cash-rich and cash-poor firms. 
References

Arellano, Manuel and stephen Bond, "Some Tests of Specification for Panel Data: Monte Carlo Evidence and an Application to Employment Equations", Review of Economic Studies, LVIII (1991), 277-97.

Beney, M. Ada, Wages, Hours, and Employment in the United States. 1214-1936, New York: National Industrial Conference Board, 1936.

Bernanke, Ben and Harold James, "The Gold Standard, Deflation, and Financial Crisis in the Great Depression: An International Comparison", in R.G. Hubbard, ed., Einancial Markets and Financial Crises, Chicago and London: University of Chicago Press, 1991.

Bernanke, Ben, "The Macroeconomics of the Great Depression: A Comparative Approach", Journal of Money, Credit, and Banking, XXVII (1995), 1-28.

Choudhri, Ehsan and Levis Kochin, "The Exchange Rate and the International Transmission of Business Cycle Disturbances: Some Evidence from the Great Depression", Jounal of Money, Credit and Banking, XII (1980), $565-74$.

Cooper, Russell, "Predetermined Wages and Prices and the Impact of Expansionary Government Policy", Reyiew of Economic studies, IVII $(1990), 205-14$.

Darby, Michael, "Three and a Half Million workers Have Been Mislaid: or An Explanation of Unemployment, 1934-41", Jounnal of Political Economy IXXXIV (1976), 1-16.

Eichengreen, Barry, Golden Fetters: The Gold Standard and the Great Depression. 1919-1939, New York: Oxford University Press, 1992.

Eichengreen, Barry and T.J. Hatton, "Interwar Unemployment in International Perspective: An Overview", in B. Eichengreen and T.J. Hatton, eds., Interwar Unemployment in International Pergpective, Dordrecht and Boston: Martinus-Nijhoff, 1988 .

Eichengreen, Barry and Jeffrey Sachs, "Exchange Rates and Economic Recovery in the 1930s", Jounpal of Fconomic History XIV (1985), 925-946.

, "Competitive Devaluation and the Great Depression: A

Theoretical Reassessment", Economics Letters, XXII (1986), 67-71.

Friedman, Milton and Anna Schwartz, A Monetary Higtory of the United States. 1867-1960, Princeton NJ: Princeton University Press for NBER, 1963.

Galenson, W. and A. Zellner, "International Comparison of Unemployment Rates", in The Measurement and Behavior of Unemployment, Universities-NBER Conference Series, no. 8, Princeton, NJ: Princeton University Press for NBER, 1957 .

Haberler, Gottfried, "The World Economy, Money, and the Great Depression", Washington DC: American Enterprise Institute, 1976. 
Hal1, Robert E., "Employment Fluctuations and Wage Rigidity", Brookings Papers on Economic Activity, 1980:1, 91-123.

Hamilton, James, "Monetary Factors in the Great Depression", Journal of Monetary Economics, XIX (1987), 145-69.

, "The Role of the International Gold Standard in Propagating the Great Depression", Contemporary Poliay Issues, VI (1988), 67-89.

League of Nations, International Trade Statistics 1937, Geneva, 1938.

League of Nations, Statistical Yearbook, various issues.

Lebergott, Stanley, Manpower in Economic Growth, New York: McGraw-Hill, 1964.

Newell, Andrew and J.S.V. Symons, "The Macroeconomics of the Interwar Years: International Comparisons", in B. Eichengreen and T.J. Hatton, eds., Interwar Unemoloyment in International Perspective, Dordrecht and Boston: Martinus-Nijhoff, 1988.

Solon, Gary, Warren Whatley, and Ann Huff Stevens, "Real Wage Cyclicality Between the World Wars: Evidence from the Ford and Byers Companies", University of Michigan, October 1993.

Temin, Peter, Lessons from the Great Depression, Cambridge MA: MIT Press, 1989.

Thorp, Rosemary, ed., Latin America in the 1930s: The Role of the Pexiphery in World Crisis, New York: St. Martin's Press, 1984.

Warren, George and F.A. Person, Gold and Prices, New York: [ED: no publisher listed] 1935. 


\section{ENDNOTES}

1. In its emphasis on monetary factors the gold standard theory is complementary to the seminal analysis of Friedman and schwartz [1963]. However, in its focus on the international finance and international political economy aspects of the story, the new view adds an important dimension which was not fully explored by Friedman and schwartz.

2. In a related paper, Bernanke and James [1991] survey the aggregate supply puzzle and investigate the role of financial crises as a mechanism through which deflation induced declines in real output. Although they find evidence for financial crisis as a transmission mechanism, the strongest effects are limited to a subset of countries and to the 1931-32 period. Thus, some additional factors are probably required to account for the entire real effect of monetary contraction and deflation. In our estimates below we attempt to control for banking crises and (indirectly) for debt-deflation and similar effects operating through the price level.

3. Although we focus on the Eichengreen-Sachs evidence, which is the best known, there have been a few other comparative studies of the period: Newell and Symons [1988] estimate "labor demand equations" for Europe, for the United Kingdom and Scandinavia separately, and for the U.S., in which employment is regressed on the real wage and the real interest rate for the period 1923-38; many of the econometric issues we raise in this paper apply to their results as well. Bernanke and James [1991] look at the links between real wages and output using a data set similar to ours, but their focus in on the role of financial crises in transmitting deflationary shocks rather than on wages. Numerous 
articles have studied wage stickiness within a single country (usually the United States); however, single-country studies lack the identifying power that cross-country differences in gold-standard policies bring to comparative analyses.

4. These papers in turn built on themes raised by (among others) Warren and Pearson [1933], Haberler [1976], and Choudhri and Kochin $[1980]$.

5. This traditional view is currently out of favor, on the grounds that it supposedly predicts a strong countercyclicality of real wages, while empirically real wages in the postwar United States appear to be acyclical or procyclical. In fact, (3) implies real-wage countercyclicality only if aggregate demand shocks are dominant; as we will see, real wages were indeed countercyclical in the interwar period, consistent with the gold standard theory's interpretation of events. The postwar U.S. experience can be reconciled with (3) if one accepts that both aggregate demand and aggregate supply shocks have hit the U.S. economy since 1945.

6. Of course, to some extent the decision to leave gold was determined by economic conditions; however, political and philosophical considerations appear to have been at least as important. See Bernanke [1995, pp. 11-12] for a discussion of why endogeneity of the exchangerate regime is unlikely to weaken the basic E-S argument.

7. In various issues of its Yearbook. The exception is the United States, for which wage data were taken from Beney [1936]. Wages are for the industrial sector; in some countries, related sectors such as mines and transport are included. We used hourly wage series for all workers wherever possible; however, for two countries, Japan and Norway, we only 
had series for daily earnings. (A partial hourly wage series for Japan exhibited behavior similar to the daily earnings series.) We did not use any weekly or monthly earnings data in order to avoid confounding changes in hourly pay with changes in workweeks, which were common during the Depression.

8. Following Bernanke and James [1991], we define "off the gold standard" loosely to encompass any major deviation from the gold standard's rules of operation, such as imposing foreign exchange controls or devaluing. See Bernanke and James [1991, Table 2.1, p. 37] for dates of changes in countries' policies with respect to the gold standard.

9. We do not mean to deny, however, that labor supply conditions-e.g., the power of unions or the extent of unemployment insurance--might have affected the speed of nominal wage adjustment and levels of employment.

10. Bernanke and James [1991] discuss several non-wage channels through which falling prices may affect output.

11. The technique is to write the estimated equation in quasidifferenced form, which produces a specification with white noise error and regression coefficients that are nonlinear functions of the serial correlation coefficient and the parameters of the original equation. The NLLS procedure imposes the nonlinear restrictions and obtains consistent and efficient estimates of all parameters.

12. Countries in our sample adhering to gold after 1931 included Belgium, France, Italy, the Netherlands, Poland, and switzerland. The U.S. also remained on gold after 1931, but we treat it as a non-gold country for reasons explained in the next note. 
13. The U.S. was at least a partial exception to this statement: Besides its great economic size, which limits the relevance of the usual "small country" model, the U.S. had at its disposal large gold reserves, which probably gave it a degree of potential control over its own money supply (although of course exactly how much control is in dispute). For these reasons we decided to treat the U.S. as a "non-gold" country with an exogenous money supply in the estimation, even though it did not leave gold until 1933. We also experimented with treating France, the dominant force in the Gold Bloc, as a "large" country with an exogenous money supply; the results were not sensitive to this latter change.

14. However, for readers concerned that imperfect capital markets or other factors might have broken the link between domestic and foreign interest rates, we note that the discount rate is a relatively poor instrument and its inclusion or exclusion has little bearing on the results.

15. Import shares are from League of Nations [1938]. We ignored imports from countries not in our 22-country sample, which in general were a very small portion of the total. Of the countries in our sample, export data from Estonia, Latvia, and New zealand were not available. In constructing import shares for Switzerland we used 1932 rather than 1929 data because the latter included bullion trade for banking transactions. Domestic currency prices of imports were calculated as the exporting country's wholesale price index times the value of the country's currency as a percentage of the 1929 gold parity (League of Nations, Statistical Yearbook, 1940/41). German data on currency values are used in place of missing Austrian data; also, for Germany 1934-36, we used the value of blocked marks (kreditsperrmark). 
16. If the abandonment of gold took place in the middle of a year, we weighted the two sets of instruments by the fraction of the year that the country was on and off the gold standard, respectively.

17. Clearly it is not literally correct that banking panics and labor unrest were independent of aggregate supply conditions. However, both of these variables have very sharp and largely unpredictable yearto-year movements, suggesting a significant random element. It is also likely that both variables reflect institutional and historical conditions only weakly related to the disturbance term in the output supply equation. For example, Bernanke and James [1991] point out that the incidence of banking panics was not well predicted by prior declines in output but instead largely reflected factors such as banking structure and national banking policies in the 1920 s.

18. To assess the magnitude of this coefficient, recall that STRIKE is measured as days lost per thousand employees. Assuming for the sake of argument that the normal work-year is 250 days, then if the effect of strikes on output is simply proportional to time lost than the coefficient on STRIKE should be $1 / 250,000$, or $.4 E-5$. In fact, the estimated value of this coefficient is .75E-5.

19. The nominal wage enters with only marginal significance in line $5(t=1.74)$, but this is clearly not a good specification.

20. Note that we assume that the wage adjustment rate is the same across countries. We did experiment with allowing the adjustment rate to depend on national union densities (for the eight or so countries for which union data are available), but we found no significant link between the speed of wage adjustment and the union variable. In taking rates of adjustment to be the same across countries, we must now 
implicitly ascribe cross-sectional differences in nominal wages conditional on prices to cross-gectional differences in the sequences of shocks to the wage adjustment equation.

21. Unemployment data for eleven countries are reported in Eichengreen and Hatton [1988, Table 1.1, p. 6]; the original sources are Galenson and zellner [1957] and Lebergott [1964]. Data for three more countries (Czechoslovakia, Japan, switzerland) were available from the ILO Yearbook. Substituting Darby's [1976] modified U.S. unemployment data for Lebergott's did not affect the overall results.

22. Employment data are from the ILO Yearbook. As we fit changes in unemployment rates only, we cannot determine the mean level of unemployment for the eight countries with fitted data and simply normalize the mean level at zero. This normalization is inconsequential for our purposes, as the estimated equations all include country fixed effects.

23. In particular, lagged unemployment may be a poor instrument if, say because of serial correlation, it is not uncorrelated with the current disturbance to the nominal wage. In this case the likely bias in the estimate of the coefficient on unemployment is positive, which could help explain the relatively weak effect of unemployment on wages found in these estimates.

24. However, the use of fixed-weight wage indexes does not correct for changes in worker quality, as when workers receive a demotion in lieu of a wage cut (Solon, Whatley, and stevens (1993)), nor does it correct for differences between official wage rates and actual wages paid. 
25. Mark Gertler and Bruce Greenwald separately suggested this point to us. 
Table I. Countries included in this study

Country Mnemonic

1. Argentina

2. Australia

3. Austria

4. Belgium

5. Canada

6. Czechoslovakia

7 Denmark

8. Estonia

9. France

10. Germany

11. Hungary

12. Italy

13. Japan

14. Latvia

15. Netherlands

16. New Zealand

17. Norway

18. Poland

19. Sweden

20. Switzerland

21. United Kingdom

22. United States
AR

AA

AU

BE

CA

CZ

DE

ES

FR

GE

HU

IT

JA

IA

NL

N2

NO

PO

SD

SW

UK

US 
Table II. NLIV estimates of the output supply equation

Dependent variable: Industrial production ( $q$ )

A. Specification: Levels, country dumnies

Sample: 1931-1936

Independent variables

\begin{tabular}{|c|c|c|c|c|c|c|}
\hline (1) & $(2)$ & (3) & (4) & (5) & & \\
\hline$w$ & $p$ & $q_{-1}$ & PANIC & STRIKE & $\hat{\rho}$ & $\alpha_{w}$ \\
\hline
\end{tabular}

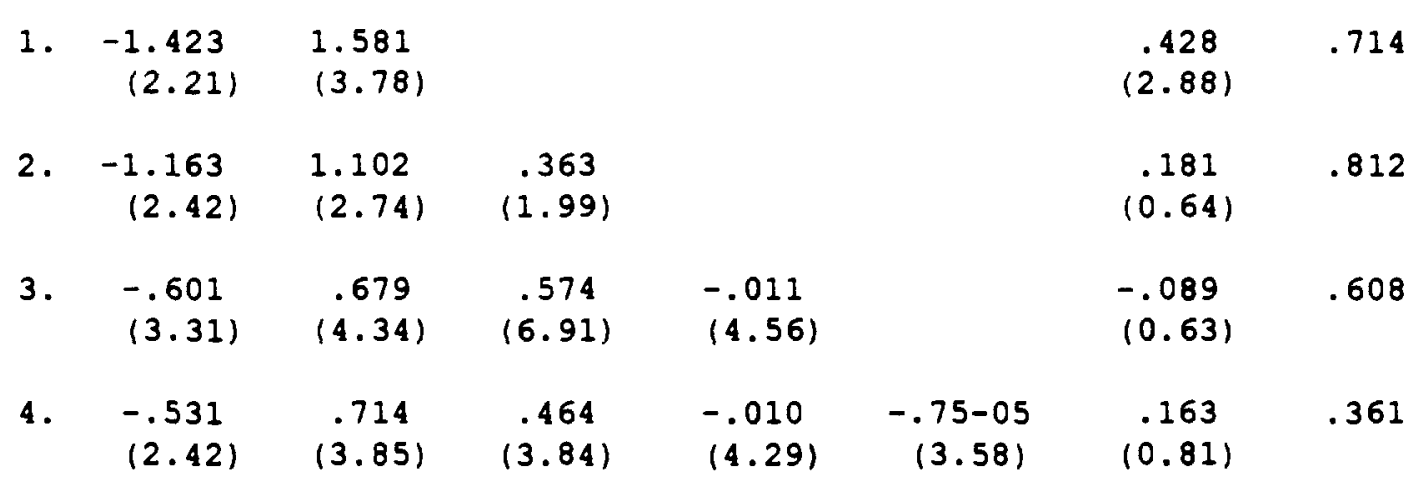

B. Specification: Differences, correction for fixed-T bias Sample: $1933-1936$

Independent variables

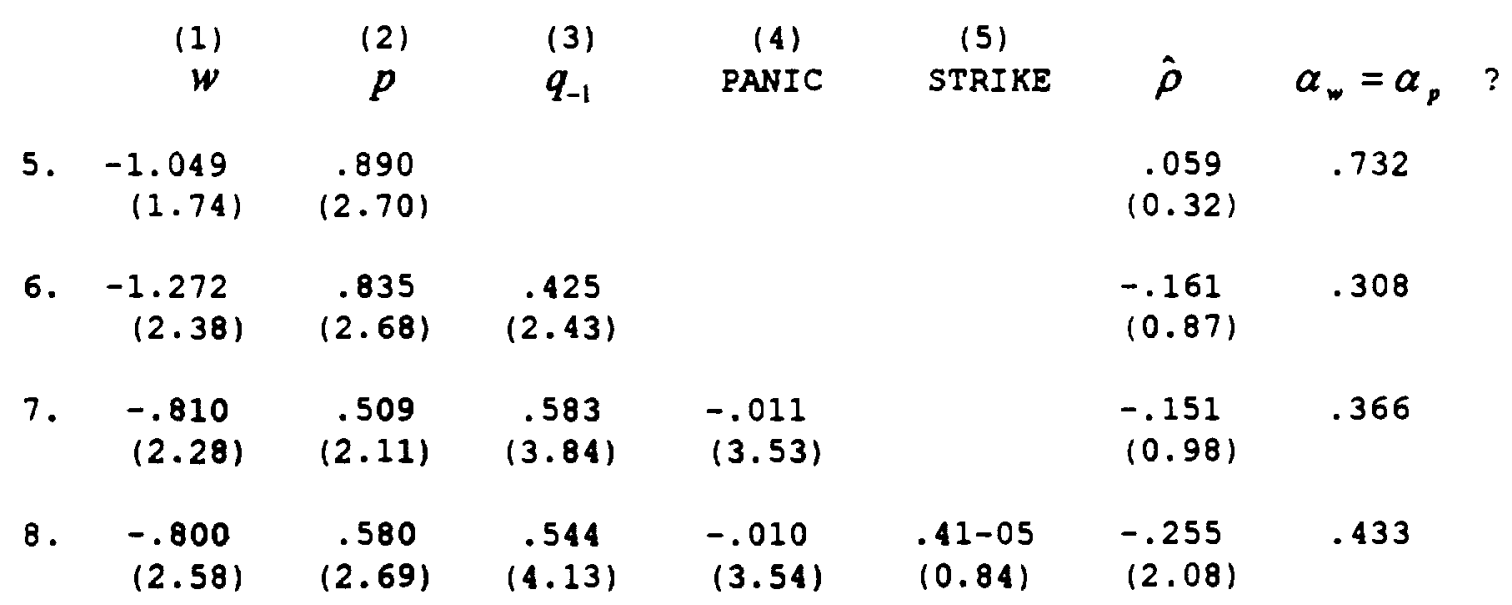

Notes: These regressions pool cross-sectional data and include time dumies. A nonlinear (quasi-differenced) specification is used to allow for consistent estimation of both the serial correlation coefficient and the coefficient on the lagged dependent variable. Absolute values of tstatistics are in parentheses. See the text for data definitions and inst ruments. 
Table III. NLIV estimates of the wage adjustment equation

Dependent variable: Nominal wage $(w)$

A. Specification: Levels, country dumies

Sample: $1931-1936$

Independent variables

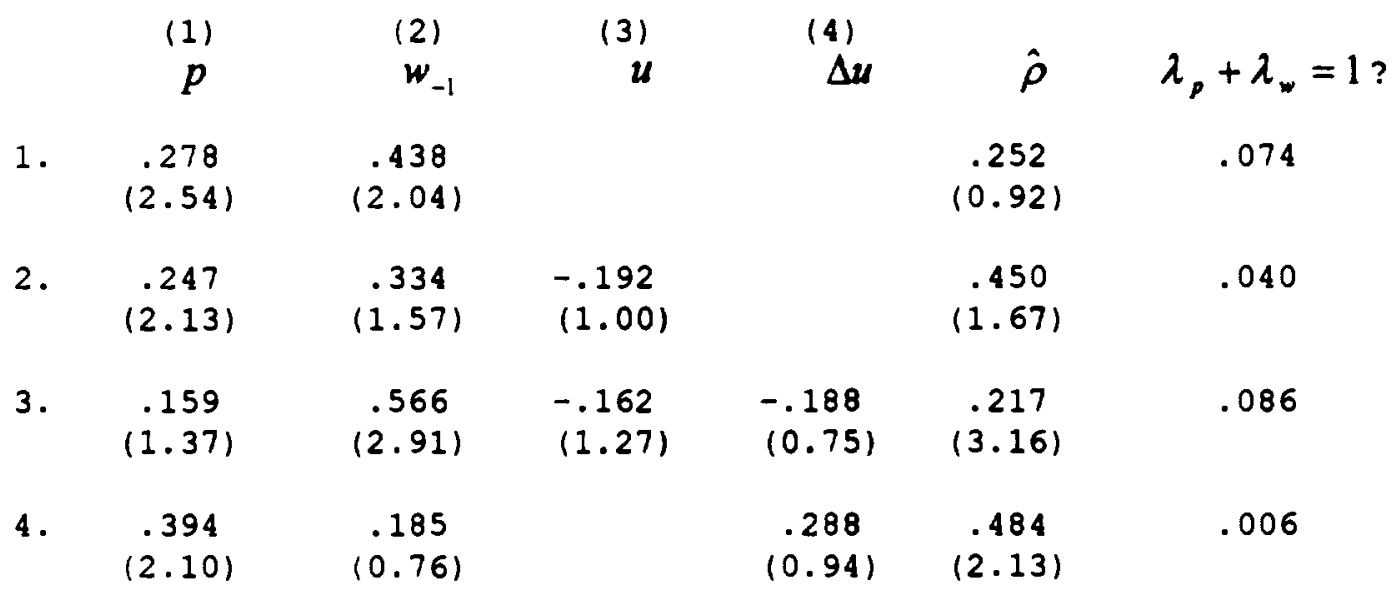

B. Specification: Differences, correction for fixed-T bias Sample: 1933-1936

Independent variables

$\begin{array}{rrr}(1) & (2) & (3) \\ p & w_{-1} & u\end{array}$

(3)

5. $\quad .329 \quad .284$

(3.14) (1.58)

$-.042 \quad .047$

6. $\begin{array}{ccc}.278 & .272 & -.161 \\ (2.70) & (1.99) & (1.09)\end{array}$

$-.171 \quad .005$

$(0.52)$

Notes: See Table II. 
Table IV. Joint estimation of aggregate supply and wage adjustment equations

\begin{tabular}{|c|c|c|c|c|}
\hline \multirow{2}{*}{ Parameter } & \multicolumn{2}{|c|}{$\begin{array}{c}\text { Levels } \\
\text { specification }\end{array}$} & \multicolumn{2}{|c|}{$\begin{array}{l}\text { Differences } \\
\text { specification }\end{array}$} \\
\hline & (A) & (B) & (c) & (D) \\
\hline 1. $\alpha$ & $\begin{array}{l}-.835 \\
(5.57)\end{array}$ & $\begin{array}{r}-.611 \\
(4.47)\end{array}$ & $\begin{array}{l}-.521 \\
(1.37)\end{array}$ & $\begin{array}{c}-.480 \\
(1.57)\end{array}$ \\
\hline 2. $\delta$ & $\begin{array}{l}.492 \\
(8.03)\end{array}$ & $\begin{array}{l}.553 \\
(9.12)\end{array}$ & $\begin{array}{l}.449 \\
(2.49)\end{array}$ & $\begin{array}{l}.409 \\
(3.01)\end{array}$ \\
\hline 3. $\beta_{\text {CRISS }}$ & $\begin{aligned}-.009 \\
(4.88)\end{aligned}$ & $\begin{array}{r}-.011 \\
(5.49)\end{array}$ & $\begin{array}{r}-.010 \\
(3.40)\end{array}$ & $\begin{aligned}-.010 \\
(3.65)\end{aligned}$ \\
\hline 4. $\beta_{\text {STRKK }}$ & $\begin{array}{r}-.65-05 \\
(3.59)\end{array}$ & $\begin{array}{r}-.69-05 \\
(3.69)\end{array}$ & $\begin{array}{r}-.59-06 \\
(0.11)\end{array}$ & $\begin{array}{l}.45-07 \\
(0.01)\end{array}$ \\
\hline 5. $\lambda_{P}$ & $\begin{array}{l}.207 \\
(2.26)\end{array}$ & $\begin{array}{l}.012 \\
(0.09)\end{array}$ & $\begin{array}{l}.335 \\
(3.30)\end{array}$ & $\begin{array}{l}.238 \\
(2.21)\end{array}$ \\
\hline 6. $\lambda_{W}$ & $\begin{array}{l}.439 \\
(2.01)\end{array}$ & $\begin{array}{l}.201 \\
(2.13)\end{array}$ & $\begin{array}{l}-.001 \\
(0.01)\end{array}$ & $\begin{array}{l}.066 \\
(0.43)\end{array}$ \\
\hline 7. $\gamma$ & - & $\begin{array}{c}-.693 \\
(3.68)\end{array}$ & - & $\begin{array}{c}-.319 \\
(1.81)\end{array}$ \\
\hline
\end{tabular}

Aggregate supply equation

$\begin{array}{rrrrr}\bar{R}^{2} & .956 & .947 & .050 & .026 \\ \text { D.W. } & 1.94 & 1.95 & 2.28 & 2.19\end{array}$

Wage adjustment equation

$\begin{array}{ccccc}\bar{R}^{2} & .911 & .903 & .402 & .448 \\ D . W . & .2 .06 & 2.09 & 1.87 & 1.95 \\ \hat{\rho}^{\omega} & .314 & .723 & - & -\end{array}$

Notes: See Table II. These results are from joint estimation of the aggregate supply and wage adjustment equations, allowing for correlation between contemporaneous equation residuals. Parameters are defined as in equations $(4)-(6)$ in the text. The bottom portion of the table reports individual-equation diagnostics. 
Figure I: Industrial Production and Real Wages in Twenty-Two Countries, 1931 - 1936
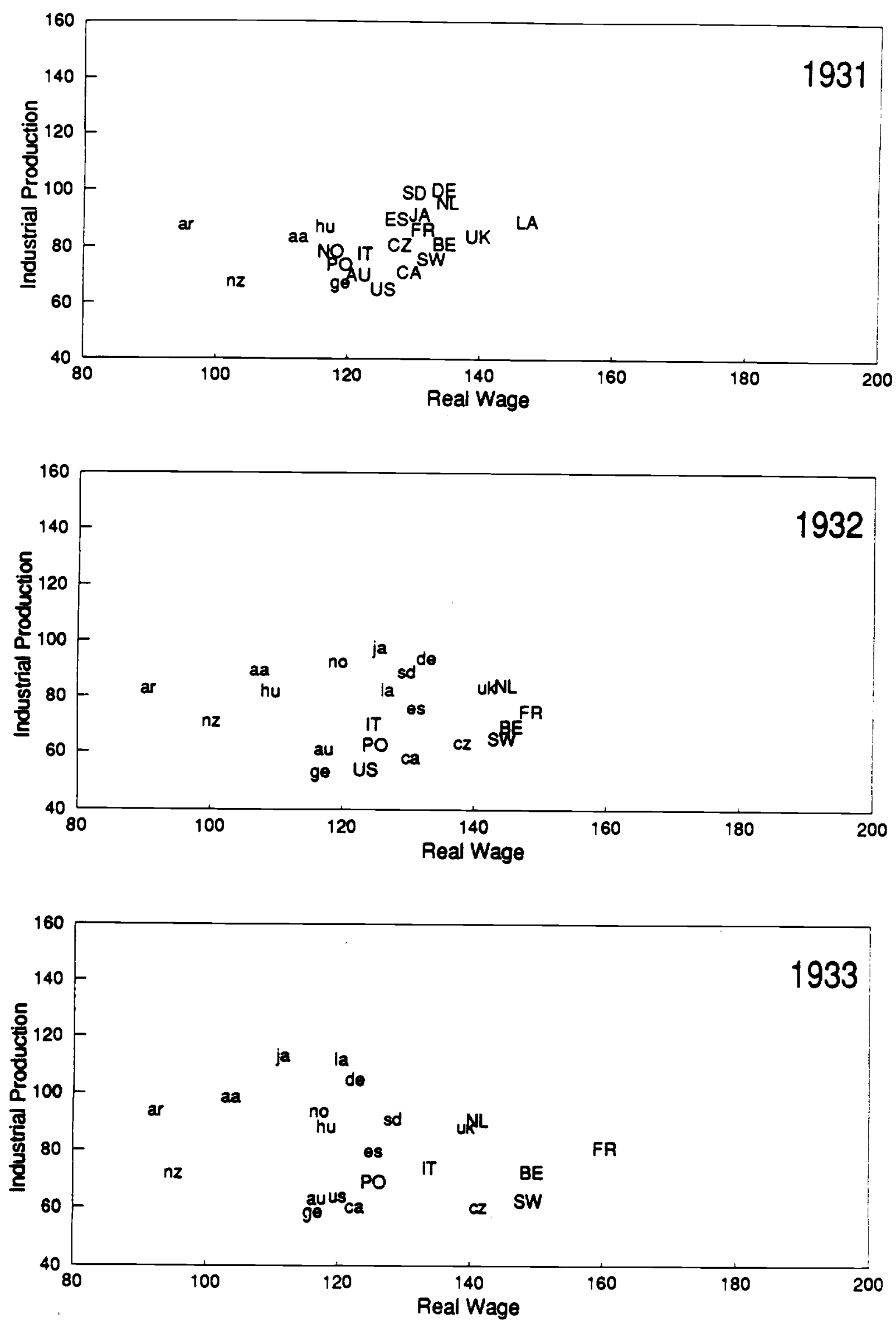
Figure I (continued)
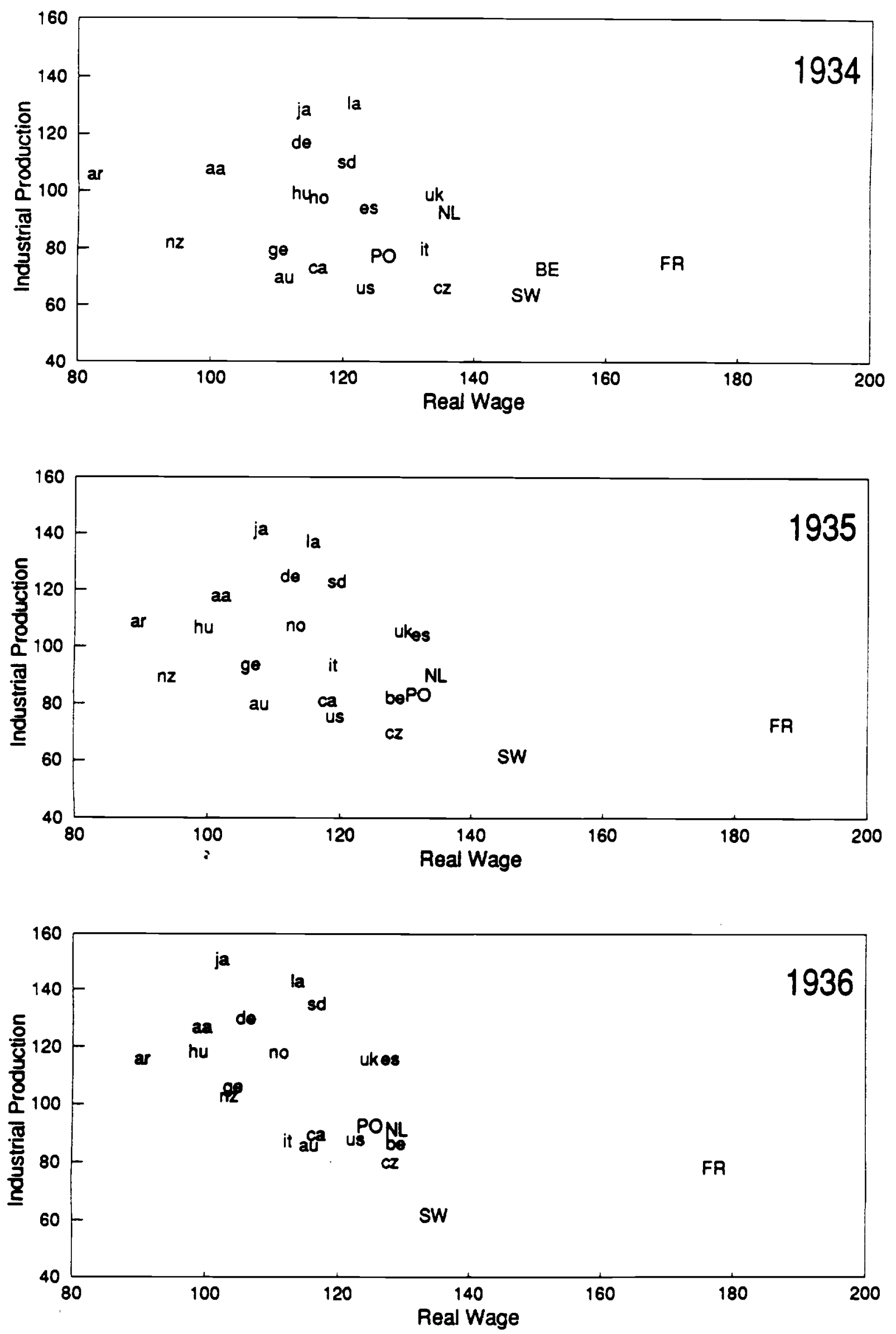